\title{
Aging-associated inflammation and fibrosis in arachnoid membrane
}

\author{
Hime Suzuki', Takeshi Mikami ${ }^{1 *}$ (D, Naotoshi Iwahara², Yukinori Akiyama', Masahiko Wanibuchi ${ }^{3}, K^{1}$ Katsuya Komatsu', \\ Rintaro Yokoyama', Tsukasa Hirano' ${ }^{1}$ Ryusuke Hosoda², Yoshiyuki Horio², Atsushi Kuno ${ }^{2}$ and Nobuhiro Mikuni ${ }^{1}$
}

\begin{abstract}
Background: The physiological and pathological significance of the arachnoid membrane (AM) is still unknown. In this study, we investigated various characteristics of the AM, focusing on the influence of inflammation and fibrosis.

Methods: Small pieces of AM sample were obtained during neurosurgical procedures from 74 cases. The clinical and pathological characteristics of the hyperplastic AM group $(\geq 50 \mu \mathrm{m})$ and the non-hyperplastic AM group (< $50 \mu \mathrm{m}$ ) were compared. Then, potential correlations between AM thickness and clinical characteristics were analyzed. Moreover, VEGFa, TGF $\beta$, and TGFa levels were quantitated by real time PCR. Then, the potential correlations between AM thickness and these inflammatory or anti-inflammatory markers, and the influence of the original disease were calculated.

Results: The median age of the patients in hyperplastic AM group was significantly older than that of the nonhyperplastic AM group. Moreover, the number of fibroblasts, $\mathrm{CD}_{6}{ }^{+}$cells, $\mathrm{CD} 86^{+}$cells, and $\mathrm{CD} 206^{+}$cells in the hyperplastic AM group was significantly higher than that in the non-hyperplastic AM group. The AM thickness was significantly correlated to age and number of fibroblasts, $\mathrm{CD} 68^{+}$cells, $\mathrm{CD} 86^{+}$cells, and CD206 ${ }^{+}$cells. The thickness of the AM was significantly correlated to the messenger RNA expression levels of VEGFa $(\rho=0.337)$, and the VEGFa expression levels were significantly correlated with TGF $\beta$ and TNFa.
\end{abstract}

Conclusions: The AM hyperplasia was influenced by aging and could be a result of inflammation and fibrosis through cytokine secretion from the inflammatory cells and fibroblasts in the AM.

Keywords: Arachnoid membrane, Inflammation, Fibrosis, Aging, Cytokine

\section{Background}

The arachnoid membrane (AM) is a tissue named "choroid meninx" by Herophilus in 3 B.C. [1]. Presently, the $\mathrm{AM}$ is considered to exist between the dura matter and pia matter and forms a subarachnoid cavity that plays a role in cerebrospinal fluid circulation. From the viewpoint of pathology, the AM comprises two laminar structures: the outer layer and inner layer $[1,2]$. The outer layer is the arachnoid barrier cell layer constructed

\footnotetext{
* Correspondence: tmikami@sapmed.ac.jp

'Department of Neurosurgery, Sapporo Medical University, Sapporo, Hokkaido, Japan

Full list of author information is available at the end of the article
}

with tight junctions, whereas the inner layer is an arachnoid reticular cell layer loosely constructed with denser cytoplasm, intermediate filaments, and mitochondria [2, $3]$. These delicate structures constitute the space of cerebrospinal fluid circulation to exclude unnecessary and harmful materials and to act as cushioning material to protect brain tissue $[1,4]$. The AM is relatively hyperplastic in the posterior fossa or around the sylvian fissure [1]. However, there are few reports on the pathological and physiological significance of AM characteristics, and the role of the AM is still not elucidated at present. 
Recently, low-level and chronic systematic inflammation has been found to influence the onset and recurrence of various lifestyle diseases [5-7]. This chronic inflammation is mainly caused by macrophages and lymphocytes through various cytokines and their polymorphisms including TNF $\alpha$, IL-6, TGF $\beta$, and VEGF [8-10], and affects the incidence of stroke or cardiovascular events through atherosclerosis [11, 12]. In addition, chronic inflammation induces fibrosis as shown in idiopathic interstitial pneumonias, constrictive pericarditis, and hepatic cirrhosis [13-17]. Such fibrosis can cause organ failure or organopathy in the final stage. The AM is an avascular tissue. Therefore, it is assumed that inflammation is hardly caused in the AM. However, from the neurosurgical perspective, during intracranial microscopic operation, varying opacity of the AM can be recognized after opening the dura, and we hypothesized that the degree of transparency of the AM might be associated with chronic inflammation and fibrosis. In this study, we investigated the various characteristics of the AM focusing on the influence of chronic inflammation and fibrosis.

\section{Methods}

\section{Description of patient population}

This study was approved by the Ethics Committee of Sapporo Medical University Hospital (no. 292-128), the Ethics Committee of Sapporo City General Hospital (H30-057-449), the Ethics Committee of Shinsapporo Neurosurgical Hospital (2018-1), the Ethics Committee of Oji General Hospital (OGH2018-16) and the Ethics Committee of Hakodate Shintoshi Hospital (2018001), and was performed in accordance with the ethical standards of the 1964 Declaration of Helsinki and its later amendments. This study was a prospective and observational study. Five institutes including our institute with sufficient surgical experience participated in the study. All patients provided informed consent before participating. From August 2017 to August 2019, the AM was obtained during neurosurgical procedure. The study included all cases in which informed consent was provided within a specified period without limiting disease specificity. In the patients with vascular disease, only the AM was obtained, whereas cerebral cortex samples were obtained along with AM in patients with brain tumor, cerebral infarction, and severe trauma. AM sampling was performed above the middle frontal gyrus, and was avoided around the Sylvian fissure, superior sagittal sinus, posterior fossa, and basal cistern because these parts are physiologically hyperplastic. The AM above the cortical artery (prefrontal or precentral artery) was dissected under a microscope, and small pieces (10-30 $\mathrm{mm}^{2}$ ) of the sample were obtained. Using the obtained samples, we assessed the following: (1) pathological characteristics of the AM, (2) messenger RNA expression of the cytokines.

\section{Preparation of the AM and pathological assessment}

For measuring the thickness of the AM in each sample, the specimens needed to be flattened and then embedded in 6.5\% Sabouraud agar (Nissui Pharmaceutical Co., Ltd., Tokyo, Japan) as a $1.0 \mathrm{~cm}$ square cube sample. For flattening the sample, 4 points of the corners of the AM were sewn on a silicon sheet (5MS01, Kono Seisakusho Co Ltd., Ichikawa, Japan) under a microscope using 100 nylon. After sewing onto the silicon sheet, the sample was infiltrated in formalin-fixation liquid for 5 days, and then embedded in $6.5 \%$ Sabouraud agar. Finally, the Sabouraud agar-embedded sample was set in paraffin. The paraffin-embedded specimens were sectioned to a thickness of $3 \mu \mathrm{m}$.

Infiltration of inflammatory cells and fibrosis was assessed by $\mathrm{H}-\mathrm{E}$ and immunohistochemical staining. CD68s (macrophage markers), CD86s (type I [M1] macrophage markers), and CD206s (type II [M2] macrophage markers) were used to assess inflammation. Antibodies against the following antigens were used for assessment: CD68 (M0876 Dako clone PG-M1; Agilent Technologies, Santa Clara, CA, USA, 1:100); rabbit antiCD86 (ab53004, Abcam plc, Cambridge, UK, 1:500); rabbit anti-mannose receptor antibody (anti-CD206; ab64693, Abcam plc, 1:200). In each sample with H-E stain, the thickness of AM was measured in 3 places and the mean value was calculated $(\mathrm{HPF}, \times 400)$. The number of fibroblasts was then counted in 3 areas of each glass slide $(\mathrm{HPF}, \times 400)$, and the mean value was calculated. In addition, the local existence of fibroblasts was assessed. Next, the number of $\mathrm{CD}^{+} 8^{+}$cells, $\mathrm{CD}^{+} 6^{+}$, and $\mathrm{CD}^{2} 06^{+}$cells were counted in 3 areas using immunohistochemical staining, and the mean value was similarly calculated.

\section{Stratification of clinical data}

Patient clinical data were stratified based on the following 11 clinical variables: (1) age; (2) sex; (3) disease; (4) smoke; (5) systolic blood pressure; (6) total cholesterol; (7) high density lipoprotein (HDL) cholesterol; (8) lowdensity lipoprotein (LDL) cholesterol; (9) glucose metabolism disorders; (10) a family history of coronary artery disease; and (11) degree of atherosclerosis. The degree of atherosclerosis was determined using the ASCVD score and Suita score $[18,19]$. The ASCVD score was advocated in the American College of cardiology and the American Heart Association guideline to evaluate prediction of the 10-year risk of development of ASCVD events. Suita score was advocated by the Japan Atherosclerosis Society guidelines for prevention of atherosclerotic cardiovascular diseases. The clinical and 
pathological factors were compared between the hyperplastic AM group $(\geq 50 \mu \mathrm{m})$ and non-hyperplastic AM group $(<50 \mu \mathrm{m})$.

\section{mRNA expression analysis using real-time qRT-PCR}

Only AM was used to assess mRNA expression. Samples with adhered blood components or brain tissue were excluded in this analysis. First, RNA extraction was performed using the RNeasy Fibrous Tissue Mini Kit (QIAGEN, Hilden, Germany) according to the manufacturer's instructions. The total RNA concentration and the A260/A280 ratio were measured using a NanoDrop Lite spectrophotometer (Thermo Fisher Scientific Inc., Waltham, MA, USA). Samples in which the A260/A280 ratio was less than 1.30 were excluded. GoScript ${ }^{\mathrm{mi}} \mathrm{Re}-$ verse Transcription Kit (Promega Corporation, WI, USA) was used to reverse-transcribe $500 \mathrm{ng}$ of total RNA. PCR was performed in a $10 \mu \mathrm{L}$ volume with $2 \mu \mathrm{L}$ of cDNA diluted 1:5. TaqMan Universal Master Mix II with UNG and TaqMan Gene Expression Assays for glyceraldehyde 3-phosphate dehydrogenase (GAPDH; Hs02786624_g1), vascular endothelial growth factor A (VEGF $\alpha$; Hs00998133_m1), transforming growth factor beta 1 (TGFß; Hs00998133_m1), and tumor necrosis factor (TNF $\alpha$; HS00174128) were purchased from Thermo Fisher Scientific Inc. qRT-PCR was performed in duplicate on the Applied Biosystems StepOnePlus ${ }^{\text {Tx }}$ (Thermo Fisher Scientific Inc., Tokyo, Japan). The thermal cycling protocol consisted of $50^{\circ} \mathrm{C}$ for $2 \mathrm{~min}$ and $95^{\circ} \mathrm{C}$ for 10 min, followed by 40 cycles of $95^{\circ} \mathrm{C}$ for $15 \mathrm{~s}$ and $60^{\circ} \mathrm{C}$ for $1 \mathrm{~min}$. The calibration curve of a reference sample with a known level of mRNA expression was used to calculate the expression level of each mRNA. Based on relative quantification, the expression of each mRNA was revised as the ratio to the reference mRNA expression (target mRNA expression/GAPDH expression). Using the mRNA expression data, correlations between the thickness of the AM and mRNA expression levels of TNF $\alpha$, TGF $\beta$, and VEGF $\alpha$ were investigated.

\section{Statistical analysis}

Data are expressed as median (interquartile range). The Mann-Whitney U test was used for comparison between the hyperplastic AM and non-hyperplastic AM groups. In addition, the male-to-female ratio and presence of clinical characteristics (disease, smoking, glucose metabolism disorders, and a family history of CAD) were compared between the hyperplastic AM and nonhyperplastic AM groups using Fisher's exact probability test. Simple regression analysis was used to compare the thickness of the AM and the potential factors or mRNA expression levels of cytokines. Spearman's correlation coefficient was used to calculate the correlation coefficients. A correlation coefficient $(\rho)$ larger than 0.7 indicated a strong correlation, a $\rho$ value between 0.5 and 0.7 indicated moderate correlation, and a $\rho<0.5$ indicated weak correlation. All statistical analyses were performed using the SPSS software package (version 24.0, IBM Corp., NY, USA), and statistical significance was set at $p<0.05$.

\section{Results}

\section{Patient data}

This study included 98 cases operated at our Hospital and an affiliated hospital from September 2017 to April 2019. Twenty-three cases could not be measured because the specimens were over-minute, or due to thermal denaturation during the preparation process. One case was excluded because the AM could not be separated from the meningioma. Consequently, 74 cases could be used to measure the thickness of the AM. Of these 74 cases, 17 cases had partially missing clinical data. The messenger RNA (mRNA) expression levels were measured completely in 57 patients. Of the 74 patients, 44 cases suffered from cerebrovascular disease, 21 cases had brain tumor, and 9 cases were of other diseases. Of the 44 cases of cerebrovascular disease, 14 cases were unruptured aneurysms, 13 cases were of moyamoya disease, 10 cases were of atherosclerotic steno-occlusive disease, 4 cases were of cerebral hemorrhage, and 3 cases were of cerebral arteriovenous malformation. Of the 21 cases of brain tumor, 7 cases were high grade glioma, 5 cases were meningioma, 3 cases were malignant lymphoma, 2 cases were low grade glioma, 1 case was ependymoma, 1 case was craniopharyngioma, 1 case was pituitary adenoma, and 1 case was metastatic carcinoma. The median (interquartile range) age of the patients at the time of surgery was 54.0 years (39.0-68.0). Thirty-one patients were male and 43 were female. The AM was collected from the frontal lobe in 29 cases, the temporal lobe in 35 cases, parietal lobe in 3 cases, occipital lobe in 4 cases, and from the cerebellum in 3 cases. The median Atherosclerotic Cardiovascular Disease (ASCVD) score and Suita score was 6.0 (2.1$24.3) \%$ and 41.0 (23.0-51.3), respectively.

\section{Pathological characteristics of the AM}

$\mathrm{H}-\mathrm{E}$ staining showed fibroblasts, fibers, and the barrier cell layer in the AM. Fibroblasts tend to exist at the inward pial side, and the fibroblast decreased at the outward dural side being replaced by fibers (Fig. 1a, b). In the 16 specimens including brain tissue, hyperplasia of the AM was observed around the arteries in 6 cases. $\mathrm{CD}^{+} 8^{+}, \mathrm{CD} 86^{+}, \mathrm{CD} 206^{+}$staining showed the infiltration of macrophages, M1 macrophages and M2 macrophages respectively, in the AM (Fig. 1c, d, e). CD68 ${ }^{+}$cells and $\mathrm{CD}^{2} \mathrm{6}^{+}$cells tended to be accumulated at inward pial side. The median thickness of AM was 49.62 (34.05- 
69.13) $\mu \mathrm{m}$. The median number of fibroblasts counted by Hematoxylin-Eosin (H-E) stain was 88.48 (41.14$125.97) \times 10^{-3} / \mu \mathrm{m}^{2}$. A total of 46 cases were stained positively for $\mathrm{CD} 68$, and the median number of $\mathrm{CD}^{+} 8^{+}$ cells was $2.85(0.00-12.56) \times 10^{-3} / \mu^{2}$. Of these 46 cases stained positively for CD68, 13 cases were stained positively for CD86 as well, and the median number of $\mathrm{CD} 6^{+}$cells was $0.00(0.00-0.00) \times 10^{-3} / \mu \mathrm{m}^{2}$. Additionally, 32 cases were stained positively for CD206, and the median number of $\mathrm{CD}^{206^{+}}$cell was $0.00(0.00-10.24) \times$ $10^{-3} / \mu^{2}$.

Table 1 shows the clinical and pathological characteristics associated with the AM thickness. We divided patients into two groups; hyperplastic AM group $(\geq 50 \mu \mathrm{m})$ and non-hyperplastic AM group $(<50 \mu \mathrm{m})$. The hyperplastic AM group and the non-hyperplastic AM group included 37 cases each. The median age of the patient was 59.0 years (45.0-70.0) in the hyperplastic AM group, and 47.0 years $(17.0-65.0)$ in the non-hyperplastic AM group indicating that the older patients exhibited hyperplastic AM $(p=0.020)$. The AM thickness was significantly correlated to age $(\rho=0.332, p=0.004)$ (Fig. 2a). Patients' sex did not affect the hyperplasia of the AM $(p=0.814)$. With regards to other clinical factors including disease, smoke, systolic blood pressure, total cholesterol, HDL cholesterol, LDL cholesterol, glucose metabolism disorders, and familial history of coronary artery disease, there was no significant difference between hyperplastic AM group and non-hyperplastic AM group. The median ASCVD score in the hyperplastic AM group [11.1 (2.2-27.2) \%] was higher than that in the non-hyperplastic AM group [4.3 (1.2-16.4) \%], though it was not significant $(p=0.176)$. The median $\mathrm{Su}-$ ita score in the hyperplastic AM group [45.0 (31.0054.00)] was higher than that in the non-hyperplastic AM group [40.0 (-1.50-48.50)] and was also not significant $(p=0.153)$. The median number of fibroblasts in the hyperplastic AM group and non-hyperplastic AM group were $110.16(69.83-138.35) \times 10^{-3} / \mu \mathrm{m}^{2}$ and 65.84 $(19.28-97.01) \times 10^{-3} / \mu \mathrm{m}^{2}$, respectively, with a significant difference between the 2 groups $(p=0.004)$. The AM thickness was significantly correlated to the number of fibroblasts $(\rho=0.336, p=0.003)$ (Fig. 2b). The median number of $\mathrm{CD}^{+} 8^{+}$cells in the hyperplastic AM group and non-hyperplastic AM group was $7.28(1.12-13.46) \times$ $10^{-3} / \mathrm{um}^{2}$ and $0.00(0.00-5.75) \times 10^{-3} / \mu^{2}$, respectively, with a significant difference $(p=0.023)$. The AM thickness was significantly correlated to the number of $\mathrm{CD}^{+} 8^{+}$cells $(\rho=0.274, p=0.018)$ (Fig. $\left.2 \mathrm{c}\right)$. The median number of $\mathrm{CD}^{+} 6^{+}$cells in the hyperplastic AM group and non-hyperplastic AM group was $0.00(0.00-9.83) \times$ $10^{-3} / \mu \mathrm{m}^{2}$ and $0.00(0.00-0.00) \times 10^{-3} / \mu^{2}$, respectively,

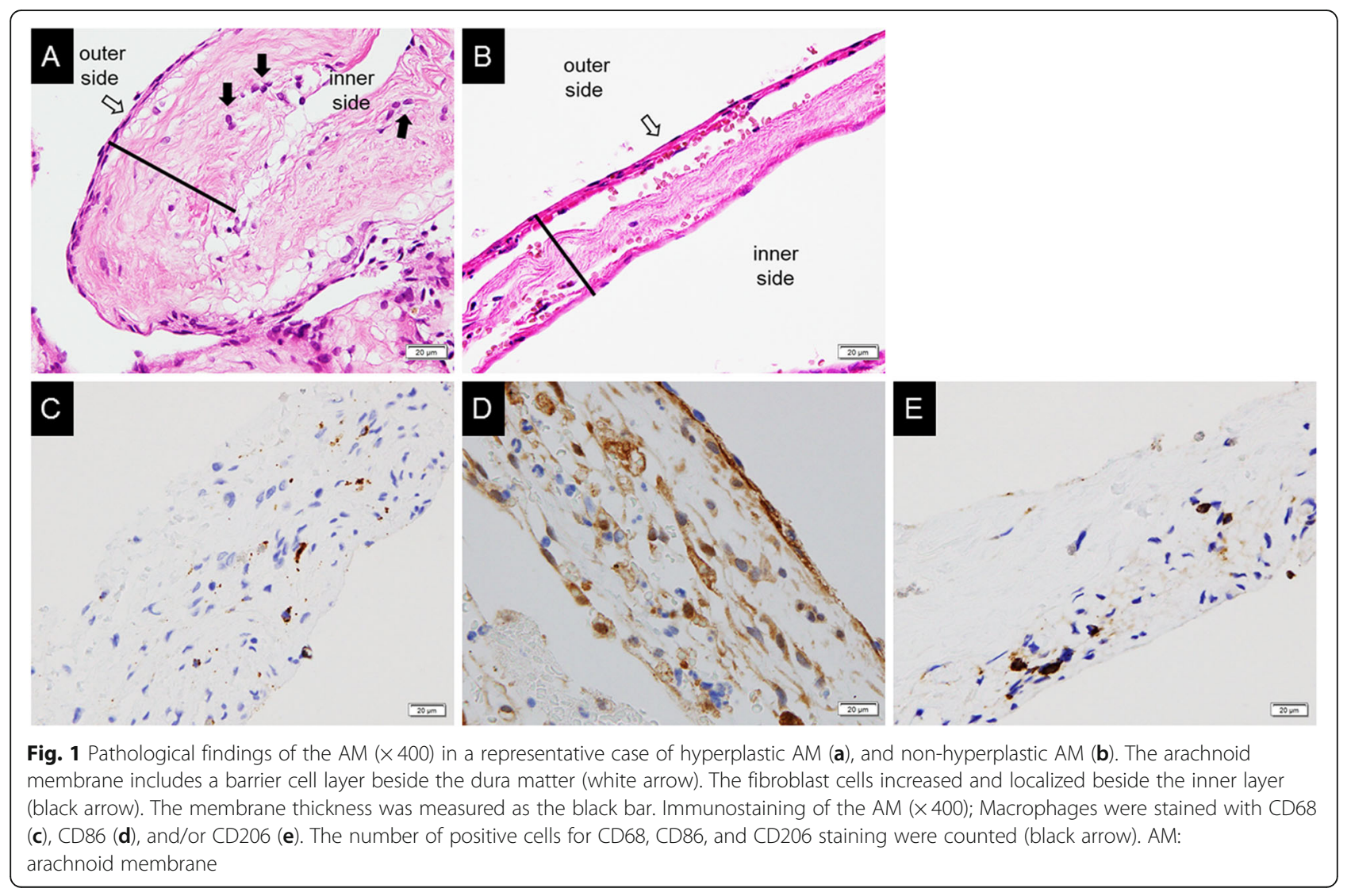


Table 1 Comparison of the characteristics of patients in the hyperplastic AM group and the non-hyperplastic AM group

\begin{tabular}{|c|c|c|c|c|}
\hline \multirow[t]{2}{*}{ Median (interquartile range) } & \multirow[t]{2}{*}{ Total } & \multicolumn{2}{|l|}{ AM thickness } & \multirow{2}{*}{$\begin{array}{l}P \\
\text { value }\end{array}$} \\
\hline & & Hyperplastic AM (50 $\mu \mathrm{m} \geqq)$ & Non-hyperplastic AM $(<50 \mu \mathrm{m})$ & \\
\hline AM thickness ( $\mu \mathrm{m})$ & $49.62(34.05-69.13)$ & $71.42(55.68-97.60)$ & $33.99(24.96-39.39)$ & $<0.001$ \\
\hline Age & $54.00(39.00-68.00)$ & $59.00(45.00-70.00)$ & $47.00(17.00-65.00)$ & 0.020 \\
\hline Sex (male/female) & $31 / 42$ & $16 / 21$ & $15 / 22$ & 0.814 \\
\hline \multicolumn{5}{|l|}{ Disease } \\
\hline Cerebrovascular disease & 44 & 23 & 21 & \multirow[t]{3}{*}{0.192} \\
\hline Brain tumor & 21 & 12 & 9 & \\
\hline Others & 9 & 2 & 7 & \\
\hline Smoke (yes/no) & $34 / 40$ & 20/17 & $14 / 23$ & 0.162 \\
\hline Systolic BP (mmHg) & $120.00(110.00-132.50)$ & $130.00(110.00-140.00)$ & $120(110.00-130.00)$ & 0.249 \\
\hline Total Cholesterol (mg/dL) & $201.00(168.50-233.00)$ & $205.00(176.00-234.50)$ & $187.00(164.00-228.00)$ & 0.465 \\
\hline $\mathrm{HDL}(\mathrm{mg} / \mathrm{dL})$ & $54.00(42.50-67.00)$ & $52.50(42.50-65.00)$ & $58.00(43.00-70.00)$ & 0.322 \\
\hline LDL (mg/dL) & $121.00(85.00-136.80)$ & $126.00(85.00-146.00)$ & $107.00(88.20-130.00)$ & 0.335 \\
\hline Glucose metabolism disorders (yes/no) & $15 / 59$ & $7 / 30$ & $8 / 29$ & 0.772 \\
\hline A family history of CAD (yes/no) & $1 / 72$ & $1 / 36$ & $0 / 36$ & 0.321 \\
\hline ASCVD score [\%] & $6.00(2.10-24.30)$ & $11.10(2.20-27.20)$ & $4.30(1.15-16.35)$ & 0.176 \\
\hline Suita score & $41.00(23.00-51.30)$ & $45.00(31.00-54.00)$ & $40.00(-1.50-48.50)$ & 0.153 \\
\hline Fibroblasts $\left(\times 10^{-3} / \mu \mathrm{m}^{2}\right)$ & $88.48(41.14-125.97)$ & $110.16(69.83-138.35)$ & $65.84(19.28-97.01)$ & 0.004 \\
\hline $\operatorname{CD} 8^{+}$cell $\left(\times 10^{-3} / \mu \mathrm{m}^{2}\right)$ & $2.825(0.00-12.57)$ & $7.28(1.12-13.46)$ & $0.00(0.00-5.75)$ & 0.023 \\
\hline $\mathrm{CD} 6^{+}$cell $\left(\times 10^{-3} / \mu \mathrm{m}^{2}\right)$ & $0.00(0.00-0.00)$ & $0.00(0.00-9.83)$ & $0.00(0.00-0.00)$ & 0.005 \\
\hline CD206 $6^{+}$cell $\left(\times 10^{-3} / \mu m^{2}\right)$ & $0.00(0.00-10.25)$ & $3.63(0.00-12.11)$ & $0.00(0.00-2.34)$ & 0.020 \\
\hline TGF $\beta$ [fold change] & $0.50(0.03-1.76)$ & $0.61(0.00-2.13)$ & $0.48(0.18-1.63)$ & 0.445 \\
\hline TNFa [fold change] & $48.02(0.00-1361.71)$ & $114.89(0.00-1008.17)$ & $32.12(0.00-1428.72)$ & 0.936 \\
\hline VEGFa [fold change] & $0.68(0.09-2.24)$ & $1.30(0.29-2.85)$ & $0.23(0.07-1.60)$ & 0.043 \\
\hline
\end{tabular}

AM Arachnoid membrane, CAD Coronary artery disease, ASCVD Atherosclerotic Cardiovascular Disease

with a significant difference $(p=0.005)$. The AM thickness was significantly correlated to the number of CD86 ${ }^{+}$cells $(\rho=0.271, p=0.020)$ (Fig. $\left.2 d\right)$. The median number of $\mathrm{CD}^{206^{+}}$cell in the hyperplastic AM group and non-hyperplastic AM group was $3.63(0.00-12.11) \times$ $10^{-3} / \mu \mathrm{m}^{2}$ and $0.00(0.00-2.34) \times 10^{-3} / \mu \mathrm{m}^{2}$, respectively, with a significant difference $(p=0.020)$. The AM thickness was significantly correlated to the number of CD206 $^{+}$cells ( $\rho=0.312, p=0.007$ ) (Fig. $\left.2 \mathrm{e}\right)$. These findings suggested that fibrosis and chronic inflammation might be seen, especially in patients with hyperplastic AM.

\section{mRNA expression of cytokines}

To investigate whether biological factors have the potential to influence the thickness of AM, we measured the mRNA levels of VEGF $\alpha$ and the thickness of AM. mRNA expression levels were measured in 58 cases, including 28 and 30 cases in the hyperplastic AM and non-hyperplastic AM groups, respectively. First, VEGF $\alpha$ was assessed because VEGF $\alpha$ is a key factor for tissue repair that is released by fibroblasts and inflammatory cells. The median value of VEGF $\alpha$ mRNA expression was $0.68(0.09-2.24)$. The median value of VEGF $\alpha$ mRNA expression levels was $1.30(0.29-2.85)$ in the hyperplastic AM group, and $0.23(0.07-1.60)$ in the nonhyperplastic AM group $(p=0.043)$. VEGF $\alpha$ mRNA expression levels were significantly correlated with the thickness of the AM $(p=0.337, p=0.010)$ (Fig. 3a). These findings indicated that AM hyperplasia is associated with VEGF $\alpha$ expression.

Next, TNF $\alpha$ and TGF $\beta$ were compared with the thickness of the AM and VEGF $\alpha$ expression, because these are representative inflammatory mediators that influence VEGF $\alpha$. Although the median values of TNF $\alpha$ and TGF $\beta$ mRNA expression levels were not significantly different between the hyperplastic AM group and the nonhyperplastic AM group ( $p=0.936$ and 0.445 respectively), VEGF $\alpha$ mRNA expression was significantly correlated with TGF $\beta$ mRNA expression $(\rho=0.703, p<0.001)$ (Fig. 3b). In addition, VEGF $\alpha$ mRNA expression was significantly correlated with TNF $\alpha$ mRNA expression $(\rho=$ 0.666, $p<0.001$ ) (Fig. 3c). These findings indicate that other inflammatory mediators, including TNF $\alpha$ and 

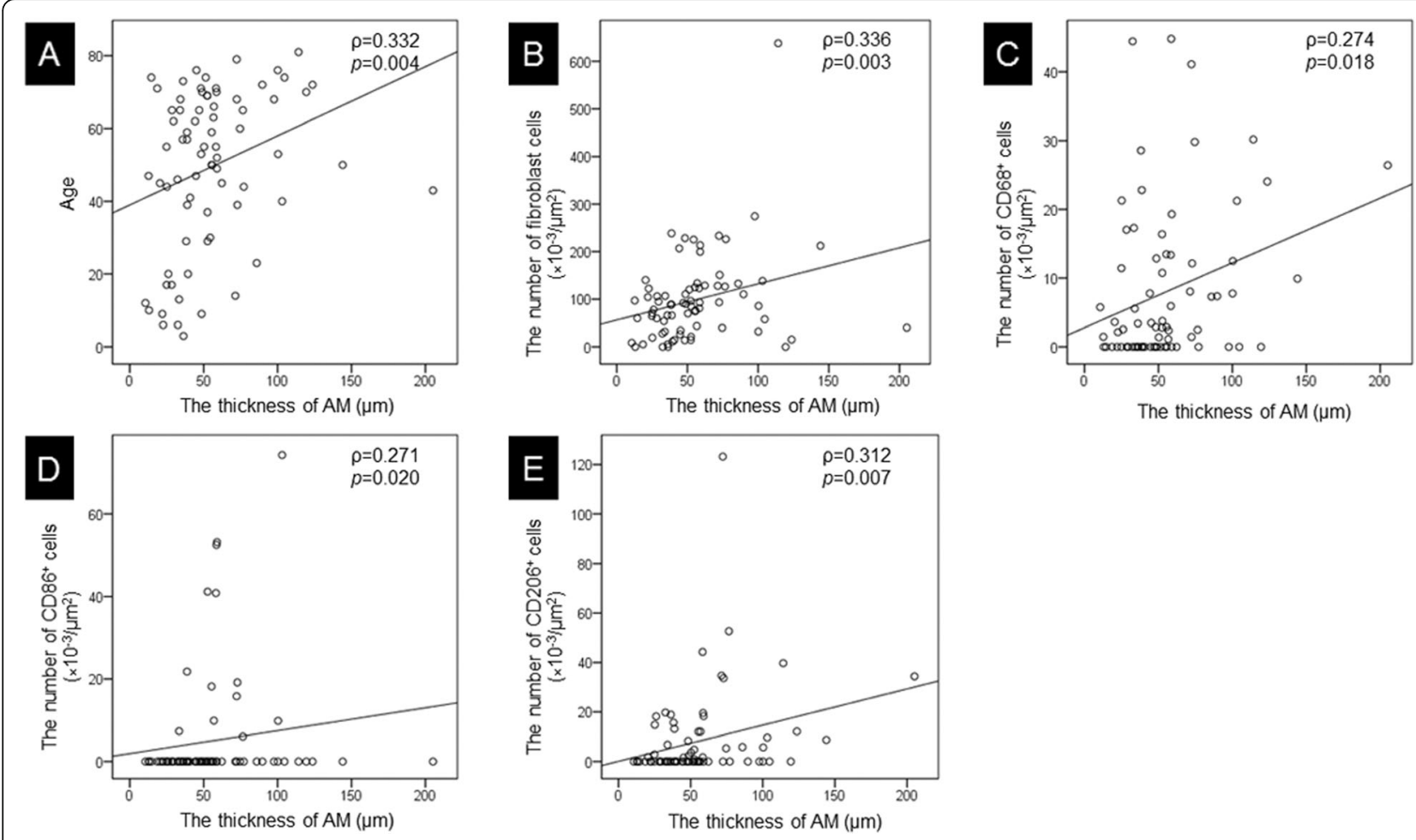

Fig. 2 Correlation between the thickness of the AM and age (a), fibroblasts (b), CD68 ${ }^{+}$cells (c), CD86 ${ }^{+}$cells $(\mathbf{d})$, and CD206 ${ }^{+}$cells $(\mathbf{e})$ cells. The correlation between these were significant ( $\rho=0.332, p=0.004 ; \rho=0.336, p=0.003 ; \rho=0.274, p=0.018 ; \rho=0.271, p=0.020 ; \rho=0.312, p=0.007$ ), respectively. AM: arachnoid membrane

TGF $\beta$, are associated with VEGF $\alpha$ and might indirectly influence AM thickness.

\section{Discussion}

In the AM, hyperplasia due to fibroblast proliferation, and infiltration of $\mathrm{CD}^{+} 8^{+}$cells, $\mathrm{CD} 86^{+}$positive cells, and $\mathrm{CD}^{206^{+}}$cells were observed, suggesting the presence of chronic inflammation focusing on macrophages in the AM. Macrophages are a key regulator of chronic inflammation and fibrosis in various disorders such as pericarditis, and hepatic cirrhosis and arteriosclerotic plaque [20-22], and in this study, among all cases, $63.5 \%$ involved $\mathrm{CD}^{+}{ }^{+}$cells. In the AM, inflammatory and anti-inflammatory cells should
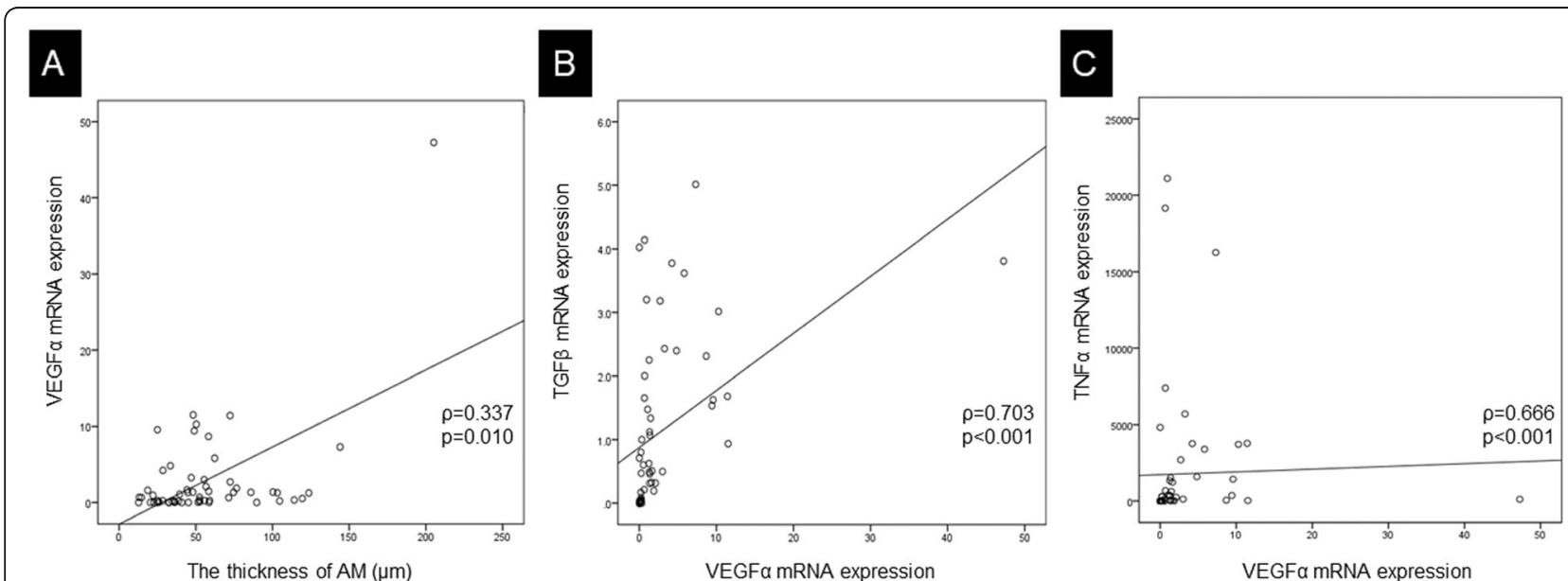

Fig. 3 Correlation between the thickness of AM and the expression levels of VEGRa, TGF $\beta$, and TGFa mRNA. The AM thickness was significantly correlated with the mRNA expression of VEGFa $(\rho=0.337, p=0.010)$ (a). VEGFa mRNA expression was significantly correlated to TGF $\beta$ mRNA expression $(\rho=0.703, p<0.001)(\mathbf{b})$, and TNFa mRNA expression $(\rho=0.666, p<0.001)$ (c). AM: arachnoid membrane 
be derived from the cerebrospinal fluid of the subarachnoid space, and/or the cerebral arteries and brain tissue. The macrophages are divided into two phenotypes varying in their physiological roles: M1 and M2 macrophages [23, 24]. The M1 macrophage appears in inflammatory conditions and promotes damage of the tissue organization by producing proinflammatory cytokines (IL-1b, TNF $\alpha$, IL-6, and IL12) [25]. On the contrary, the M2 type macrophages appear in anti-inflammatory conditions and produces anti-inflammatory cytokines (IL-10, IGF-1, and TGF $\beta$ ) working in phagocytosis and restoration of tissue organization [25]. The distribution of various macrophage phenotypes is considered to allow prediction of the inflammatory stage. In atherosclerosis, some reports show that the dominance of M1 macrophages results in a vicious cycle of plaque formation [26]. In this study, $17.6 \%$ were $\mathrm{CD}^{+} 6^{+}$cells and $43.2 \%$ were $\mathrm{CD}^{206^{+}}$cells, and the M2 marker was superior. The M2 macrophages facilitate healing and repairing of the inflammatory process, show anti-inflammatory action, and promote fibrosis [23]; it is thought that these cells contribute to hyperplasia of the AM. Further, TGF $\beta$ and TNF $\alpha$ in the AM were strongly correlated in this study. M1 and M2 macrophages coexist in various inflammatory states, and dynamic changes in the M1/M2 phenotype of recruited mononuclear phagocytes have been observed in other disease model as well [27-29].

Fibroblast proliferation is observed in the regeneration process of chronic inflammation due to antiinflammatory cytokines [30]. Our results indicate that the infiltration of chronic inflammatory cells and fibroblasts tends to distribute in the inner layer adjacent to the brain surface, and that extracellular matrix including collagen fibers mainly exists at the dura matter side, in the barrier cell layer. It was considered that the AM hyperplasia originates from the inner side of the AM, and that inflammation begins from the subarachnoid space near the arteries (Fig. 4). TGF $\beta$ causes tissue fibrosis due to the proliferation of fibroblasts and production of extracellular matrix [31]. In this study, VEGF $\alpha$ levels correlated with the thickness of the AM. VEGF $\alpha$ is produced by several types of cells including fibroblasts and inflammatory cells $[32,33]$. In moyamoya disease, high VEGF expression was correlated with TGF $\beta$ [34], and might be associated with abnormal vascular hyperplasia. Although the pathological meaning of excessive AM hyperplasia is still obscure, in other organs including the lung, liver, and kidney, excessive fibrosis leads to defective repair and induces organ failure in the final stages $[27,35]$. In the brain, fibrosis of the AM might affect the pulsative circulation of cerebrospinal fluid. Recently, the glymphatic system of the perivascular and subarachnoid space has gained attention and has been shown to be associated with Alzheimer's disease [36]. In future work, understanding the harmful effect of AM hyperplasia on the glymphatic system or cognitive function will be crucial. From the clinical viewpoint, only aging was associated with the AM thickness in this study. Progressive fibrosis is a hallmark of the aging process and has been implicated in the pathogenesis of diseases of the heart, lungs, liver, kidneys, and bone marrow [37]. Contrary to expectations, there were no correlations between the AM hyperplasia and clinical factors, including atherosclerosis scores. In stroke, chronic cerebral ischemic

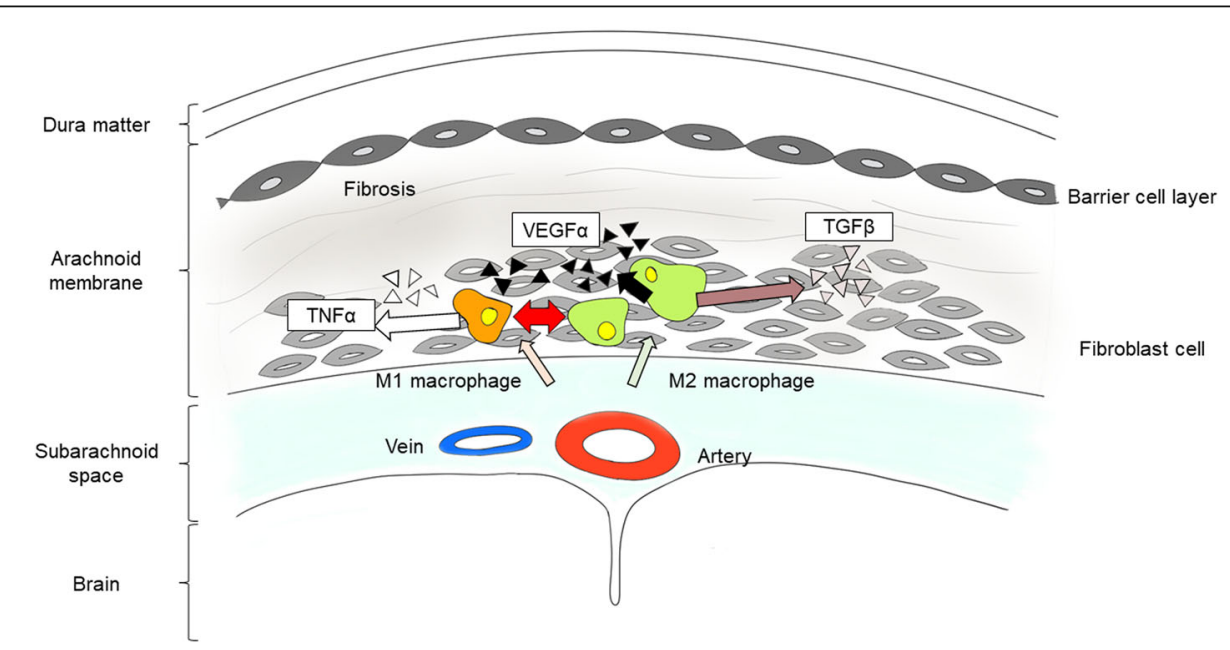

Fig. 4 Illustration of the process of AM hyperplasia. Fibroblasts and VEGFa play an important role in AM hyperplasia. Infiltration of macrophages though chronic inflammation tends to distribute inward to the pial side adjacent to the brain surface, and the extracellular matrix including collagen fibers mainly exists at the outward dural side. Macrophage activation accelerates the elevation of TNFa and TGF $\beta$ and promotes fibrosis. Consequently, VEGFa levels increase in the AM. The depicted image is our own design. AM: arachnoid membrane 
state, brain tumor, and brain abscess, these pathologies should be a state of microglia or macrophage activation $[38,39]$, though the influence of each pathology was minimal in the AM. Therefore, it will be necessary to compare the groups with equivalent ages to assess the influence of the disease.

There are some limitations to this study. First, this study included various kinds of diseases, and the degree of the disease was different in each case. For instance, local factors might depend on the stage of the original disease especially in extra-axial tumors. On the other hand, it was considered that the AM could be affected widely in chronic ischemic disease, though the degree of the ischemia was different in each case. This study did not exclude the influences of disease specificity. Secondly, the quantity of specimens was not sufficient for analysis by real-time qRT-PCR. Samples in which the A260/A280 ratio was set less than 1.30 were excluded in this study, though their value was relatively low. Third, there were problems in terms of AM fixation. Because $\mathrm{AM}$ is a very thin and delicate tissue, thermal denaturation might have occurred in the Sabouraud agar fixation process. Although, an alternative technique is needed to assess the cerebral environment, this could not be achieved to find pathological significance.

In conclusion, AM hyperplasia was influenced by aging. Pathologically, fibroblasts and M2 macrophages proliferated in the inward pia side especially around the arteries. AM hyperplasia was correlated with VEGF $\alpha$ and might be a result of anti-inflammatory changes and fibrosis. These alterations might be affected by cerebral ischemia, especially in moyamoya disease. Further analysis of the AM in various diseases And more number of cases will provide us with answers to some of these hypothesis.

\section{Conclusion}

In conclusion, AM hyperplasia was influenced by aging. Pathologically, fibroblasts and M2 macrophages proliferated in the inward pia side especially around the arteries. AM hyperplasia was correlated with VEGF $\alpha$ and might be a result of anti-inflammatory changes and fibrosis. Further analysis of the AM in various diseases and more number of cases will provide us with answers to some of these hypothesis.

\section{Abbreviations}

AM: Arachnoid membrane; mRNA: Messenger RNA; ASCVD: Atherosclerotic Cardiovascular Disease; H-E: Hematoxylin-Eosin

\section{Acknowledgments}

The authors would like to thank Dr. Shintoro Sugita and Professor Tadashi Hasegawa for their guidance in pathological assessment. Data were provided by Dr. Masayoshi Takigami and Dr. Yoshifumi Horita, Sapporo City General Hospital, Dr. Masahito Fujishige and Dr. Akinori Yamamura, Shinsapporo Neurosurgical Hospital, Dr. Toshimi Honma, Oji General Hospital, and Dr.
Shunya Ohtaki, Dr. Yasuhiro Takahashi, and Dr. Kohichi Haraguchi, Hakodate Shintoshi Hospital.

\section{Authors' contributions}

HS and TM analyzed and interpreted the patient data regarding the thickness of arachnoid membrane and the influence of inflammation and fibrosis. NI, RH, YH, and AK assessed mRNA expression analysis using realtime qRT-PCR. YA, MW, KK, RY, TH, and NM provided surgical specimens and data. All authors read and approved the final manuscript.

\section{Funding}

This investigation was supported by the JSPS KAKENHI (18 K16591) and JSPS KAKENHI (20 K09352). The funding body had no role in the conception/ design of the study, data collection, analysis or interpretation, or the writing/ approval of the manuscript.

\section{Availability of data and materials}

The datasets used and/or analyzed during the current study are available from the corresponding author on reasonable request. The data are not publicly available due to privacy or ethical restrictions.

\section{Declarations}

\section{Ethics approval and consent to participate}

All procedures performed in studies involving human participants were in accordance with the ethical standards of the institutional research committee (The ethics committee of Sapporo Medical University Hospital, the Ethics Committee of Sapporo City General Hospital (H30-057-449), the Ethics Committee of Shinsapporo Neurosurgical Hospital (2018-1), the Ethics Committee of Oji General Hospital (OGH2018-16) and the Ethics Committee of Hakodate Shintoshi Hospital (2018001)) with the 1964 Helsinki declaration and its later amendments or comparable ethical standards. Similarly, each institution participated in this study provided ethics approval to conduct this study. All participants provided written informed consent and were able and willing to participate.

\section{Consent for publication}

Not applicable.

\section{Competing interests}

The authors declare that they have no competing interests.

\section{Author details}

${ }^{1}$ Department of Neurosurgery, Sapporo Medical University, Sapporo, Hokkaido, Japan. ${ }^{2}$ Department of Pharmacology, Sapporo Medical University, Sapporo, Hokkaido, Japan. ${ }^{3}$ Department of Neurosurgery, Osaka Medical and Pharmaceutical University, Takatsuki, Osaka, Japan.

Received: 29 October 2020 Accepted: 13 April 2021

Published online: 21 April 2021

\section{References}

1. Adeeb N, Deep A, Griessenauer CJ, Mortazavi MM, Watanabe K, Loukas M, et al. The intracranial arachnoid mater: a comprehensive review of its history, anatomy, imaging, and pathology. Childs Nerv Syst. 2013;29(1):1733. https://doi.org/10.1007/s00381-012-1910-x.

2. Haines DE, Harkey HL, al-Mefty O. The "subdural" space: a new look at an outdated concept. Neurosurgery. 1993;32(1):111-20. https://doi.org/10.1227/ 00006123-199301000-00017.

3. Alcolado R, Weller RO, Parrish EP, Garrod D. The cranial arachnoid and pia mater in man: anatomical and ultrastructural observations. Neuropathol Appl Neurobiol. 1988;14(1):1-17. https://doi.org/10.1111/j.1365-2990.1988. tb00862.x.

4. Louveau A, Smirnov I, Keyes TJ, Eccles JD, Rouhani SJ, Peske JD, et al. Structural and functional features of central nervous system lymphatic vessels. Nature. 2015;523(7560):337-41. https://doi.org/10.1038/nature14432.

5. Ross R. Atherosclerosis--an inflammatory disease. N Engl J Med. 1999;340(2): 115-26. https://doi.org/10.1056/nejm199901143400207.

6. Franceschi C, Campisi J. Chronic inflammation (inflammaging) and its potential contribution to age-associated diseases. J Gerontol A Biol Sci Med Sci. 2014;69(Suppl 1):S4-9. https://doi.org/10.1093/gerona/glu057. 
7. Minamino T, Komuro I. Vascular aging: insights from studies on cellular senescence, stem cell aging, and progeroid syndromes. Nat Clin Pract Cardiovasc Med. 2008;5(10):637-48. https://doi.org/10.1038/ncpcardio1324.

8. Gordon S. Alternative activation of macrophages. Nat Rev Immunol. 2003; 3(1):23-35. https://doi.org/10.1038/nri978.

9. Martinez FO, Helming L, Gordon S. Alternative activation of macrophages: an immunologic functional perspective. Annu Rev Immunol. 2009;27(1):45183. https://doi.org/10.1146/annurev.immunol.021908.132532.

10. Atsumi T, Singh R, Sabharwal L, Bando H, Meng J, Arima Y, et al. Inflammation amplifier, a new paradigm in cancer biology. Cancer Res. 2014;74(1):8-14. https://doi.org/10.1158/0008-5472.can-13-2322.

11. Moore KJ, Tabas I. Macrophages in the pathogenesis of atherosclerosis. Cell. 2011;145(3):341-55. https://doi.org/10.1016/j.cell.2011.04.005.

12. Back M, Yurdagul A Jr, Tabas I, Oorni K, Kovanen PT. Inflammation and its resolution in atherosclerosis: mediators and therapeutic opportunities. Nat Rev Cardiol. 2019. https://doi.org/10.1038/s41569-019-0169-2.

13. Travis WD, Costabel U, Hansell DM, King TE Jr, Lynch DA, Nicholson AG, et al. An official American Thoracic Society/European Respiratory Society statement: update of the international multidisciplinary classification of the idiopathic interstitial pneumonias. Am J Respir Crit Care Med. 2013;188(6): 733-48. https://doi.org/10.1164/rccm.201308-1483ST.

14. Syed FF, Schaff HV, Oh JK. Constrictive pericarditis--a curable diastolic heart failure. Nat Rev Cardiol. 2014;11(9):530-44. https://doi.org/10.1038/nrcardio.2 014.100 .

15. Koyama Y, Brenner DA. Liver inflammation and fibrosis. J Clin Invest. 2017; 127(1):55-64. https://doi.org/10.1172/jci88881.

16. Wynn TA, Barron L. Macrophages: master regulators of inflammation and fibrosis. Semin Liver Dis. 2010;30(3):245-57. https://doi.org/10.1055/s-0030-12 55354.

17. Racanelli AC, Kikkers SA, Choi AMK, Cloonan SM. Autophagy and inflammation in chronic respiratory disease. Autophagy. 2018;14(2):221-32. https://doi.org/10.1080/15548627.2017.1389823.

18. Nishimura K, Okamura T, Watanabe M, Nakai M, Takegami M, Higashiyama A, et al. Predicting coronary heart disease using risk factor categories for a Japanese urban population, and comparison with the Framingham risk score: the Suita study. J Atheroscler Thromb. 2014;21(8):784-98. https://doi org/10.5551/jat.19356.

19. Goff DC Jr, Lloyd-Jones DM, Bennett G, Coady S, D'Agostino RB, Gibbons R, et al. 2013 ACC/AHA guideline on the assessment of cardiovascular risk: a report of the American College of Cardiology/American Heart Association Task Force on Practice Guidelines. Circulation. 2014;129(25 Suppl 2):S49-73. https://doi.org/10.1161/01.cir.0000437741.48606.98.

20. Medbury HJ, James V, Ngo J, Hitos K, Wang Y, Harris DC, et al. Differing association of macrophage subsets with atherosclerotic plaque stability. Int Angiol. 2013;32(1):74-84

21. Jager NA, Teteloshvili N, Zeebregts CJ, Westra J, Bijl M. Macrophage folate receptor-beta (FR-beta) expression in auto-immune inflammatory rheumatic diseases: a forthcoming marker for cardiovascular risk? Autoimmun Rev. 2012;11(9):621-6. https://doi.org/10.1016/j.autrev.2011.11.002.

22. Wolfs IM, Donners MM, de Winther MP. Differentiation factors and cytokines in the atherosclerotic plaque micro-environment as a trigger for macrophage polarisation. Thromb Haemost. 2011;106(5):763-71. https://doi. org/10.1160/th11-05-0320.

23. Mantovani A, Biswas SK, Galdiero MR, Sica A, Locati M. Macrophage plasticity and polarization in tissue repair and remodelling. J Pathol. 2013; 229(2):176-85. https://doi.org/10.1002/path.4133.

24. Sica A, Mantovani A. Macrophage plasticity and polarization: in vivo veritas. J Clin Invest. 2012;122(3):787-95. https://doi.org/10.1172/jci59643.

25. Gordon S, Martinez FO. Alternative activation of macrophages: mechanism and functions. Immunity. 2010;32(5):593-604. https://doi.org/10.1016/j. immuni.2010.05.007.

26. Boyle JJ. Macrophage activation in atherosclerosis: pathogenesis and pharmacology of plaque rupture. Curr Vasc Pharmacol. 2005;3(1):63-8. https://doi.org/10.2174/1570161052773861.

27. Wynn TA, Vannella KM. Macrophages in tissue repair, regeneration, and fibrosis. Immunity. 2016;44(3):450-62. https://doi.org/10.1016/j.immuni.2016. 02.015 .

28. Ricardo SD, van Goor H, Eddy AA. Macrophage diversity in renal injury and repair. J Clin Invest. 2008;118(11):3522-30. https://doi.org/10.1172/jci36150.

29. Swirski FK, Nahrendorf M, Etzrodt M, Wildgruber M, Cortez-Retamozo V, Panizzi $P$, et al. Identification of splenic reservoir monocytes and their deployment to inflammatory sites. Science (New York, NY). 2009;325(5940): 612-6. https://doi.org/10.1126/science.1175202.

30. Das A, Sinha M, Datta S, Abas M, Chaffee S, Sen CK, et al. Monocyte and macrophage plasticity in tissue repair and regeneration. Am J Pathol. 2015; 185(10):2596-606. https://doi.org/10.1016/j.ajpath.2015.06.001.

31. Meng XM, Nikolic-Paterson DJ, Lan HY. TGF-beta: the master regulator of fibrosis. Nat Rev Nephrol. 2016;12(6):325-38. https://doi.org/10.1038/ nrneph.2016.48.

32. Zhao Y, Adjei AA. Targeting angiogenesis in cancer therapy: moving beyond vascular endothelial growth factor. Oncologist. 2015;20(6):660-73. https://doi.org/10.1634/theoncologist.2014-0465.

33. Carmeliet $P$, Jain RK. Molecular mechanisms and clinical applications of angiogenesis. Nature. 2011;473(7347):298-307. https://doi.org/10.1038/na ture10144.

34. Weng L, Cao X, Han L, Zhao H, Qiu S, Yan Y, et al. Association of increased Treg and Th17 with pathogenesis of moyamoya disease. Sci Rep. 2017;7(1): 3071. https://doi.org/10.1038/s41598-017-03278-8.

35. Mescher AL. Macrophages and fibroblasts during inflammation and tissue repair in models of organ regeneration. Regeneration (Oxford, England). 2017:4(2):39-53. https://doi.org/10.1002/reg2.77.

36. Rasmussen MK, Mestre $H$, Nedergaard M. The glymphatic pathway in neurological disorders. Lancet Neurol. 2018;17(11):1016-24. https://doi.org/1 0.1016/s1474-4422(18)30318-1.

37. Jiang S, Li T, Yang Z, Yi W, Di S, Sun Y, et al. AMPK orchestrates an elaborate cascade protecting tissue from fibrosis and aging. Ageing Res Rev. 2017;38: 18-27. https://doi.org/10.1016/j.arr.2017.07.001.

38. Wolf SA, Boddeke HW, Kettenmann H. Microglia in physiology and disease. Annu Rev Physiol. 2017;79(1):619-43. https://doi.org/10.1146/annurevphysiol-022516-034406.

39. Yoshida Y, Hiwasa T, Machida T, Kobayashi E, Mine S, Matsushima J, et al. Elevation of autoantibody in patients with ischemic stroke. Neurol Med Chir. 2018;58(7):303-10. https://doi.org/10.2176/nmc.ra.2018-0022.

\section{Publisher's Note}

Springer Nature remains neutral with regard to jurisdictional claims in published maps and institutional affiliations.
Ready to submit your research? Choose BMC and benefit from:

- fast, convenient online submission

- thorough peer review by experienced researchers in your field

- rapid publication on acceptance

- support for research data, including large and complex data types

- gold Open Access which fosters wider collaboration and increased citations

- maximum visibility for your research: over $100 \mathrm{M}$ website views per year

At $\mathrm{BMC}$, research is always in progress.

Learn more biomedcentral.com/submissions 